\title{
Defining Strategies for Peptic Ulcer Treatment: A Helicobacter pylori Economic Cost Model
}

\author{
Chris M. Kozma, W. Michael Dickson, Timothy A. Mullenix, and C.E. Reeder
}

\begin{abstract}
This article describes an economic model for evaluating Helicobacter pylori ( $H$. pylori) eradication and conventional treatment of peptic ulcer disease. The model was developed using decision analytic techniques with literature-based estimates of probabilities, cost, and population sizes. One-way sensitivity analysis was conducted varying costs and probabilities over relevant ranges. Decision points used in the model include endoscopy, tests for $H$. pylori presence, and use of maintenance therapy. Chance relationships include probabilities of ulcer, presence of $H$. pylori, eradication of $H$. pylori, success of treatment, compliance, and recurrence. The outcome measure is first-year cost of peptic ulcer management.

Results support the use of $H$. pylori eradication. Savings depend on the rate of endoscopy and expense of eradication therapies. The model suggests that costs may be reduced if patients with a prior history of ulcer are targeted for empiric $H$. pylori eradication therapy.
\end{abstract}

Our findings suggests a three-stage approach to treating peptic ulcer disease if first-year costs are considered. Patients who initially present with symptoms consistent with ulcer should be treated with conventional therapy. If one or more recurrences are experienced, then ulcer diagnosis can be considered as substantiated and $H$ : pylori eradication is indicated. Endoscopy should be conducted if more serious disease is suspected or if patient is nonresponsive to conventional or $H$. pylori eradication therapies. Managed care organizations should develop and communicate ulcer management strategies that consider both eradication and conventional treatment.

KEY WORDS: Economic, Ulcer, H. pylori model, Disease state management

J Managed C̣are Pharm 1998; 4: 205-20

\section{Authors}

CHRIS M. KOZMA, PH.D., Assistant Professor; W. MICHAEL DICKSON, PH.D., Professor; TIMOTHY A. MULLENIX, M.S., PHARM. D., Associate Professor; and C.E. REEDER, PH.D., Professor and Associate Dean, are members of the Center for Outcomes Research and Evaluation at the University of South Carolina, College of Pharmacy, Columbia, SC.

AUTHOR CORRESPONDENCE: Chris M. Kozma, Ph.D., University of South Carolina College of Pharmacy, Columbia, SC 29208.

ACKNOWLEDGMENT: Funding for development of this model was provided by McAdams, Inc, on behalf of Glaxo Wellcome Pharmaceuticals, Inc.

Copyright (C) 1998, Academy of Managed Care Pharmacy, Inc. All rights reserved.
$\mathrm{T}$ his article develops a literature-based cost model for Helicobacter pylori (H. pylori) eradication and contrasts it with a conventional treatment model for ulcer disease. An understanding of $\mathrm{H}$. pylori eradication program costs is important because the National Institutes of Health consensus development panel recommends $H$. pylori eradication as a first-line therapy for treatment of duodenal ulcer. ${ }^{1}$

Several economic models have demonstrated the effect of $H$. pylori eradication on ulcer recurrence, compared the use of endoscopic testing versus empiric therapy, and compared alternative pharmaceutical therapies. ${ }^{2-7}$ This model differs from other published models by estimating the total cost of peptic ulcer treatment for various treatment strategies in selected patient populations. The proposed cost-analysis model provides a theoretical basis for forecasting costs of an H. pylori eradication program. Many managed care organizations (MCOs) develop and implement disease state management programs with the expectation that such programs will lower treatment costs while maintaining or improving the quality of care. This model gives MCOs a method to estimate peptic ulcer treatment costs for different-treatment strategies in their patient populations, using their databases.

Increased understanding of peptic ulcer disease and $H$. pylori infection has led to the development of pharmaceutical 


\section{Table 1. Patient Groups for Whom Population Size} Estimates Are Needed

$\Delta$ New patients (no history of ulcer/not on maintenance therapy)

$\Delta$ Existing patients with history of ulcer/on maintenance therapy

A Existing patients with history of ulcer/not on maintenance therapy

A Existing patients with no history of ulcer/on maintenance therapy

A Existing patients with no history of ulcer/not on maintenance therapy

therapies with the potential to cure the disease, thereby eliminating the costs of ulcer recurrence. Potential savings from improvements in ulcer treatment are intuitively obvious; however, the potential costs of treatment may not be as clear. For example, if program implementation results in increased use of diagnostic procedures, such as endoscopy and $H$. pylori presence tests, costs will increase. Unneeded costs may be incurred if patients who are not appropriate candidates for therapy are treated. Literature suggests there is no evidence that patients who have nonulcer dyspepsia (gastritis) should be treated with $H$. pylori eradication therapy. ${ }^{2}$ More research is needed to document this supposition. Clinically acceptable and economically favorable treatment of peptic ulcer disease may be enhanced by management strategies such as targeting patients who should receive diagnostic tests, improving patient medication compliance, and choosing between $H$. pylori eradication and conventional ulcer treatment. The proposed model attempts to elucidate the economic consequences of various treatment strategies

\section{MODEL COMPONENTS AND ASSUMPTIONS}

The model covers a 12 -month period. An H. pylori eradication program that eliminates the need for maintenance therapy will result in savings that exceed those in the one-year model presented. Furthermore, the model assumes that the population size within the $\mathrm{MCO}$ is constant over the period modeled. Being literature-based, the model may not reflect actual costs or disease prevalence within a particular MCO, but it should provide a general framework for analysis. Using these assumptions, the model was developed in four stages:

$\Delta$ estimation of population size for $H$. pylori eradication and conventional therapy cost comparisons;

$\boldsymbol{\Delta}$ development of a decision tree to model the flow of major decisions, chance events, and outcomes associated with $H$ pylori eradication and conventional ulcer treatment;

$\boldsymbol{\Delta}$ assignment of probabilities and costs to the events and outcomes for each path of the decision tree; and

A sensitivity analysis for key analysis variables.

Model specification begins by stipulating four key treatment decisions. The first decision involves using endoscopy to verify an ulcer diagnosis versus using empiric therapy (decision 1). This diagnostic decision exists for both the conventional and $H$. pylori eradication treatment arms of the model. In the case of $H$. pylori eradication, if endoscopy was performed, the assumption was that a biopsy or serum test for $H$. pylori would also have been conducted

A second critical decision was whether to include serum testing for the presence of $H$. pylori before (decision 2) and after (decision 3) empiric therapy to determine if eradication therapy was successful. Finally, a maintenance therapy decision node was included in the conventional arm (decision 4).

This combination of decisions presents seven possible scenarios for $H$. pylori eradication patients and 13 possible scenarios for conventional therapy patients. Within each of these scenarios, several pathways could be followed based on diagnostic test results, therapy success or failure, and whether (for the conventional model) patients were placed on maintenance therapy.

Decisions regarding H. pylori eradication or conventional treatment differ among patient groups (e.g., use of endoscopy, eradication tests, maintenance therapy). To account for this

Table 2. Decision Scenarios and Outcome Pathways for the H. pylori Eradication Portion of the Model

\begin{tabular}{|c|c|c|c|c|}
\hline Scenario Number & $\begin{array}{c}\text { Endoscopy and Biopsy } \\
\text { or Serum Test }\end{array}$ & Serum Test Only & Eradication Test & $\begin{array}{l}\text { Number of Possible } \\
\text { Outcomes or Pathways }\end{array}$ \\
\hline \multicolumn{5}{|c|}{ 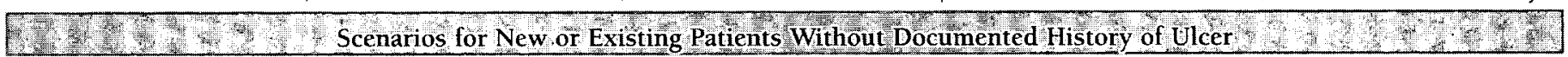 } \\
\hline Scenario 1 & YES & NO & YES & 5 \\
\hline Scenario 2 & YES & NO & $\mathrm{NO}$ & 4 \\
\hline Scenario 3 & NO & YES & YES & 5 \\
\hline Scenario 4 & $\mathrm{NO}$ & YES & NO & 4 \\
\hline Scenario 5 & NO & NO & NO & 3 \\
\hline \multicolumn{5}{|c|}{ 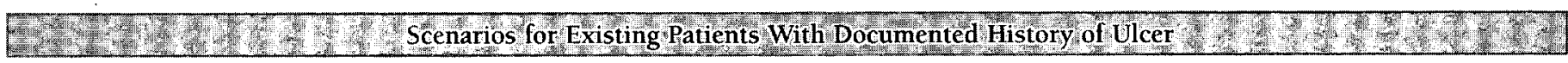 } \\
\hline Scenario 6 & NO & NO & YES & 4 \\
\hline Scenario 7 & $\mathrm{NO}$ & NO & NO & 3 \\
\hline
\end{tabular}


variation, five patient groups were identified (see Table 1). These patient groups were selected because recurrence rates and treatment needs are likely to differ among them. For example, a new patient (i.e., no prior history of complaint) may be more likely to undergo diagnostic testing than an existing patient on maintenance therapy. Also, patients on maintenance therapy should be less likely to experience recurrence than patients who do not receive maintenance therapy.

New patients, by definition, have no history of ulcer and are not on maintenance therapy. Existing patients are identified by prior use of acute-level dosing of an antiulcer medication. History of ulcer is defined either by previous endoscopy or by the number of recurrences of acute therapy a patient has experienced (an MCO's database should have data to identify both inclusion criteria). For example, patients who have received three courses of acute therapy (i.e., three courses of acute-level dosing, each lasting six to eight weeks) over a two-year period are assumed to have a history of ulcer even if an endoscopic procedure was not performed. Using this logic, a patient without a documented history of ulcer could be classified as an existing ulcer patient. This could occur when a patient has received two courses of acute therapy and has no evidence of endoscopy. Tables 2 and 3 present the scenarios and possible pathways for H. pylori eradication and conventional treatment for the patient groupings listed in Table
1. Note that for the H. pylori eradication arm of the model, the patient groupings are reduced to two; prior treatment is irrelevant since the approach to eradication is the same in this model. Existing patients without a documented history of ulcer are treated as if they were new patients.

There are multiple pathways for each decision scenario because each decision may have different results. For example, if endoscopy is performed, patients may be either positive or negative for ulcer. The right-hand columns of Tables 2 and 3 show the number of pathways that result from the decisions.

\section{Literature-Based Estimation of Patient Groupings}

The next stage in model development is estimation of the population sizes for each of the five patient groups listed in Table 1. The literature did not provide estimates of population sizes for all five groups. When estimates were not available, sample sizes were extrapolated or approximated, based on the opinion of the authors and three clinical pharmacist consultants.

For the purpose of illustrating this model, a managed care population of 100,000 enrollees was assumed. The lifetime prevalence of ulcer disease in the United States is $8 \%$, and approximately $1.8 \%$ of the population will experience active ulcer during any year. ${ }^{9}$ This means that at any time a total of

Table 3. Decision Scenarios and Outcome Pathways for the Conventional Portion of the Model

\begin{tabular}{l|c|c|c}
\hline Scenario Number & Endoscopy & Maintenance Therapy & $\begin{array}{c}\text { Number of Possible Outcomes } \\
\text { or Pathways }\end{array}$ \\
\hline & & S & Scenarios \\
\hline Scenario 1 & YES New Patients & YES & 8 \\
\hline Scenario 2 & YES & NO & 6 \\
\hline Scenario 3 & NO & YES & 7 \\
\hline Scenario 4 & NO & NO & 5 \\
\hline
\end{tabular}

W. Scenarios for Existing Patients with No Documented History of Ulcer Not Currently Using Maintenance Therapy $c^{2}$. W

\begin{tabular}{l|c|c|c}
\hline Scenario 5 & YES & YES & 7 \\
\hline Scenario 6 & YES & NO & 5 \\
\hline Scenario 7 & NO & YES & 6 \\
\hline Scenario 8 & NO & NO & 4 \\
\hline
\end{tabular}

5. Scenarios for Existing Patients with Documented History of Ulicer Currently Using Maintenance Therapy

Scenario 9

NO

YES

6

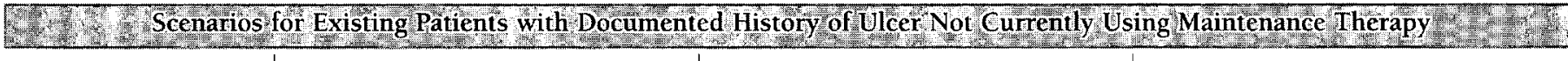

Scenario 10

Scenario 11

NO

NO

YES

6

S Scenarios for Existing Pătients with No Documented Hîtồry of Ulcer Cûrrently Using Maintenance Therapy

Scenario 12

Scenario 13

YES

YES

YES

7

$\mathrm{NO}$

6 
Table 4. Group Size Estimates

\begin{tabular}{l|c|c}
\hline \multicolumn{1}{c|}{ Group } & $\begin{array}{c}\text { Number and Percentage of Patients } \\
\text { Expected per 100,000 Enrollees }\end{array}$ & Calculation* \\
\hline & $234(3 \%)$ & $(100,000 \times 0.018 \times 0.13)$ \\
\hline New patients & $1,635(20 \%)$ & $(1,566 \times 0.75 \times 0.6)+(6,200 \times .25 \times .6)$ \\
\hline $\begin{array}{l}\text { Existing patients on maintenance therapy } \\
\text { with ulcer history }\end{array}$ & $1,090(14 \%)$ & $(1,566 \times 0.75 \times 0.4)+(6,200 \times .25 \times .4)$ \\
\hline $\begin{array}{l}\text { Existing patients on maintenance therapy } \\
\text { with no ulcer history }\end{array}$ & $1,860(23 \%)$ & $(6,200 \times 0.75 \times 0.4)$ \\
\hline $\begin{array}{l}\text { Existing patients not on maintenance } \\
\text { therapy with ulcer history }\end{array}$ & $3,181(40 \%)$ & $(1,566 \times 0.25)+(6,200 \times .75 \times .6)$ \\
\hline $\begin{array}{l}\text { Existing patients not on maintenance } \\
\text { therapy with no ulcer history }\end{array}$ & $8,000(100 \%)$ & \\
\hline \begin{tabular}{l} 
TOTAL \\
\hline
\end{tabular}
\end{tabular}

*Note: The 1,566 patients were identified using the following calculation: $(8,000$ total patients $\times 0.018$ active $)-(234$ new patients $)=1,566$. The 6,200 patients were identified using the following calculation: $(100,000$ in population $\times 0.08$ with ulcer disease $)-(1800)=6,200$, where 1,800 represents the total number of active ulcer patients in a year $(8,000 \times 0.018)=1,800$.

8,000 patients in this hypothetical population could be expected to carry an ulcer diagnosis. These 8,000 patients will be distributed among the five patient groups in Table 1. Likewise, the total number of patients (new and existing) with active ulcer within any given year is $1,800(100,000$ patients $x$ 0.018). Peer-reviewed literature suggests that approximately one of every eight patients (13\%) with active ulcer during any one-year period will be "first-time" ulcer patients. ${ }^{3,9,10}$ Based on this estimate, there are $234(1,800$ patients $\times 0.13)$ new ulcer patients and $7,766(8,000$ patients-234 patients) who are either "existing active" ( 1,800 x $0.87=1,566)$ or "existing but not active" $(7,766-1,566=$ $6,200)$ ulcer patients. These 7,766 ulcer patients are categorized by whether or not they receive maintenance treatment. Literature reports suggest that approximately $80 \%$ of ulcer patients will experience recurrence over a one- to two-year period. "Accepted ulcer therapy recommends that maintenance therapy should be used upon ulcer recurrence. For the model, we assumed that approximately $75 \%$ of "existing active" ulcer patients will be on maintenance therapy and $25 \%$ of the "existing but not active" patients will be on maintenance therapy. Finally, patients must be categorized by whether they have a documented history (by endoscopy or number of recurrences) of ulcer. Since there were no data available in the literature for these groups, we estimated that approximately $60 \%$ of patients on maintenance therapy would have a history of ulcer based on endoscopy or recurrence, and for those not on maintenance therapy these percentages were reversed (i.e., $40 \%$ of nonactive patients not on maintenance will have a history of ulcer). We selected a mid-range value because it is likely that this percentage will vary substantially among organizations due to variations in demographics, case-mix, and types of providers. These percentages were varied in a sensitivity analysis to evaluate their impact on costs. MCOs may be able to evaluate their paid medical claims data to calculate actual prevalence of ulcer. Table 4 presents the final population size estimates for each patient group.

\section{Decision Tree Models}

Because the decision tree is large ( 84 unique pathways), it cannot be depicted it here. However, the decision and chance nodes from the tree are shown in Table 5, and an example of two arms of the tree (one for conventional treatment and one for H. pylori eradication) is included in Appendix A. The values of chance variables differed depending on the patient group being modeled. Values for chance variables were determined from the literature, except where assumptions were necessary, as noted in the introduction.

These decision and chance variables can be combined to represent 32 events for the $H$. pylori eradication portion of the model and 96 events for the conventional treatment portion of the model. For example, if the decision is made to conduct endoscopy, the patient may then test positive for ulcer and $\mathrm{H}$. pylori and receive treatment, but symptoms do not resolve. Each of these combinations is associated with an event probability.

The probabilities for all chance nodes are presented in Appendix B. To investigate whether changes in the probabilities would affect results, each probability was varied in a one-way sensitivity analysis. The size of the model precludes a discussion here of each pathway.

Evidence from the literature indicates that approximately $20 \%-25 \%$ of subjects who present with dyspeptic symptoms have an ulcer ${ }^{12,13}$ Therefore, the starting point for the model was that $25 \%$ of new patients presenting with ulcer symptoms would be demonstrated by endoscopy to have an ulcer, while $75 \%$ would not. This estimate was used in both the $H$. pylori eradication and conventional models.

Walsh and Peterson ${ }^{14}$ have reported cure rates with $H$. 
Table 5. Decision and Chance Nodes Used in Conventional Treatment and H. pylori Eradication Decision Subtree

\begin{tabular}{|c|c|c|}
\hline Variable & Variable Type & Description \\
\hline Endoscopy with biopsy & Decision & Conduct test or use empiric therapy \\
\hline Serum test for H. pylori & Decision & $\begin{array}{l}\text { Test or not test after treatment if endoscoped } \\
\text { or before and after empiric treatment }\end{array}$ \\
\hline Eradication test H. pylori & Decision & Test or not test after treatment \\
\hline Results of endoscopy and biopsy & Chance & $\begin{array}{l}\text { Probability of being positive or negative for } \\
\text { H. pylori and ulcer }\end{array}$ \\
\hline Results of treatment & Chance & $\begin{array}{l}\text { Probability that symptoms return or do not } \\
\text { return after treatment or retreatment }\end{array}$ \\
\hline Eradication testing & Chance & $\begin{array}{l}\text { Probability that } H \text {. pylori has been eradicated } \\
\text { or not eradicated }\end{array}$ \\
\hline Results of $H$. pylori presence test & Chance & $\begin{array}{l}\text { Probability that } H \text {. pylori is present or not } \\
\text { present }\end{array}$ \\
\hline \multicolumn{3}{|c|}{ 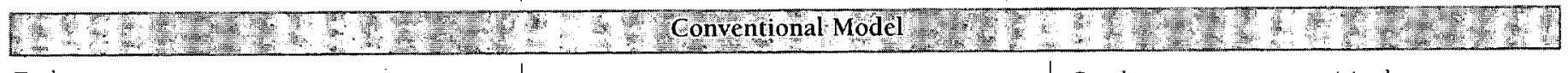 } \\
\hline Endoscopy & Decision & Conduct test or use empiric therapy \\
\hline Maintenance therapy & Decision & Use or do not use maintenance therapy \\
\hline Results of endoscopy & Chance & $\begin{array}{l}\text { Probability of being positive or negative for } \\
\text { ulcer. }\end{array}$ \\
\hline Results of acute ulcer treatment & Chance & $\begin{array}{l}\text { Probability that symptoms do or do not } \\
\text { resolve after treatment or retreatment }\end{array}$ \\
\hline Symptom recurrence & Chance & $\begin{array}{l}\text { Probability that symptoms do or do not recur } \\
\text { after acute treatment or retreatment }\end{array}$ \\
\hline Patient medication compliance & Chance & $\begin{array}{l}\text { Probability that patients will or will not be } \\
\text { compliant }\end{array}$ \\
\hline
\end{tabular}

pylori eradication therapies in excess of $90 \%$. The starting values used for "no return of symptoms" was $90 \%$ after either treatment or retreatment with eradication therapy for patients who receive endoscopy and $67 \%$ for patients who were treated empirically. The difference in cure rate reflects the view that a higher percentage of empirically treated patients will have symptoms that will not be relieved by $H$. pylori eradication treatment (e.g., nonulcer dyspepsia, gastroesophageal reflux disease), thus resulting in a lower symptom resolution percentage. ${ }^{15,16}$ This assumption was based on clinical judgment and not on the literature.

The final set of probabilities in the H. pylori eradication model focuses on the use of tests to determine if $H$. pylori is present. The literature suggests that efficacy rates for antibiotic therapy in $H$. pylori eradication treatment are similar for initial treatment and retreatment. ${ }^{17}$ Therefore, a value of $90 \%$ was used for the probability of a negative test for presence of $H$. pylori following eradication therapy.

A similar, literature-based, approach was used to assign probabilities for the conventional model. The literature suggests that $75 \%-85 \%$ of patients with confirmed ulcer will heal during a four-to-eight-week course of conventional therapy, and about $60 \%$ will recur over the next 12 months if maintenance therapy is not utilized. "If patients are placed on maintenance therapy and remain compliant, the recurrence rate will be significantly lower. An estimate of $40 \%$ was used in the model based on the authors' judgment. This estimate was varied over a wide range in the sensitivity analysis. Conventional wisdom and experience show that a high percentage of patients will be noncompliant; however, there were no estimates in the literature for compliance with antiulcer maintenance therapy. Using clinical judgment, $75 \%$ of patients were estimated to be compliant; the effects of variation in this estimate were tested in the sensitivity analysis.

Combining all these events results in 23 pathways for the H. pylori eradication model and 61 for the conventional model. Pathwaýs that ended in treatment failure were assumed to be referred, and the cost of referral was included in the cost estimates. Costs beyond referral were not included in the model. The range of cost estimates used in the model and sensitivity analyses are shown in Table 6.

Because the model is estimated for a fixed period, the number of months for which new patients will have an opportunity to use maintenance therapy decreases over time and, 
Table 6. Estimated Cost Ranges for H. pylori Eradication and Conventional Treatment

\begin{tabular}{l|c}
\hline Description & Cost Range \\
\hline \begin{tabular}{l|l}
\hline Endoscopy & H. pylori Eradication \\
\hline H. pylori presence test when conducted \\
with endoscopy (either by biopsy or titer)
\end{tabular} & $\$ 50-\$ 300$ \\
\hline $\begin{array}{l}\text { H. pylori eradication therapy } \\
\text { H. pylori eradication test (urea breath test) }\end{array}$ & $\$ 50-\$ 300$ \\
\hline $\begin{array}{l}\text { Referral to physician outside H. pylori } \\
\text { eradication program (for treatment failures) }\end{array}$ & $\$ 50-\$ 400$ \\
\hline $\begin{array}{l}\text { Second course of H. pylori eradication } \\
\text { therapy }\end{array}$ & $\$ 50-\$ 200$ \\
\hline $\begin{array}{l}\text { H. pylori presence test (serum only, } \\
\text { including titer, not biopsy) }\end{array}$ & $\$ 50-\$ 300$ \\
\hline $\begin{array}{l}\text { H. pylori eradication test (serum only, } \\
\text { including titer, not biopsy) }\end{array}$ & $\$ 50-\$ 300$ \\
\hline $\begin{array}{l}\text { Referral to physician outside conventional } \\
\text { treatment program (for treatment failures) }\end{array}$ & $\$ 50-\$ 400$ \\
\hline $\begin{array}{l}\text { Cost of a physician office visit for recurrence } \\
\text { Endoscopy . }\end{array}$ & $\$ 20-\$ 100$ \\
\hline $\begin{array}{l}\text { Acute ulcer therapy (8 weeks) } \\
\text { Maintenance therapy (l month) }\end{array}$ & $\$ 50-\$ 200$ \\
\hline
\end{tabular}

therefore, the differential effects of time must be included. In addition, existing patients who are on maintenance therapy and develop an active ulcer will revert to acute-level dosing. Costs for maintenance therapy will be adjusted to reflect this change in dosing. Acute therapy may vary from one to three months.

A compliance factor was also included because patients who may be considered compliant are likely to have some variation in use and noncompliant patients probably use some medication. Finally, patients experiencing recurrence will have different numbers of episodes. For example, existing patients on maintenance therapy are likely to experience a lower number of recurrences per year, on average, than existing patients who are not on maintenance therapy. These modifications to the cost calculations of Table 6 are presented in Table 7 .

Cost estimates for the $H$. pylori eradication and conventional models were developed by applying the formulas below to each pathway. Where a parameter is not applicable, its contribution is zero.

\section{Table 7. Factors Used in Cost Calculations}

\begin{tabular}{|c|c|}
\hline Factor & Range of Values \\
\hline Maintenance therapy & $\begin{array}{l}2.0-5.5 \text { months for new patients } \\
12 \text { months for existing patients on } \\
\text { maintenance } \\
4.5-10 \text { months for existing patients not } \\
\text { on maintenance }\end{array}$ \\
\hline Acute therapy & $1-3$ months \\
\hline Compliance & $\begin{array}{l}60 \%-100 \% \text { for compliant patients } \\
0 \% \text { to } 50 \% \text { for noncompliant patients }\end{array}$ \\
\hline Number of recurrences & $\begin{array}{l}0 \text { No recurrence } \\
1-\text { Single recurrence } \\
1.0-2.0 \text { for multiple recurrences }\end{array}$ \\
\hline
\end{tabular}

\section{H. pylori Eradication Cost Formula}

Cost for pathway $=$ endoscopy $+(H$. pylori test $)+(H$ pylori eradication therapy $)+(H$. pylori eradication test $)+$ (second course of $H$. pylori eradication therapy) + (cost of referral if therapy fails).

\section{Conventional Therapy Cost Formula}

Cost for pathway $=$ endoscopy + (initial acute ulcer treatment) + (acute ulcer treatment) (number of recurrences) + (average cost of maintenance)(maintenance factor)(compliance)-(number of recurrences)(acute factor)(average cost of maintenance therapy)(compliance) + (cost of physician visit)(number of recurrences) + (cost of referral if treatment fails).

\section{RESULTS AND DISCUSSION}

Tables 8 and 9 present the results for the H. pylori eradication and conventional portions of the model. The model allows users to specify the percentage of patients who will follow each scenario. For example, in the conventional model, $30 \%$ of the patients were estimated to follow scenarios one and four while $20 \%$ would follow scenarios two and three. These decisions were based on clinical judgment. Existing patients on maintenance therapy with a history of ulcer have only one scenario because none of these patients receive endoscopy and continue on maintenance therapy after a recurrence. Tables 8 and 9 may be entered into spreadsheets, and the sensitivity of the model to the effects of moving patients from one category to another can be simulated. In this manner, effects such as induced demand for endoscopy if an $\mathrm{H}$. pylori eradication program is implemented versus continuing with conventional therapy could be incorporated

Under the assumptions made in this model, the results suggest that implementation of an H. pylori eradication pro- 
gram has the potential to generate cost savings. Tables 8 and 9 show significant differences in cost depending on the mode of therapy. Though patients who receive endoscopy would be expected to have much higher costs than those who do not receive endoscopy, the model suggests a strategy for achieving similar therapeutic results at a reduced cost. Patients with suspected ulcer disease could be started on conventional therapy. Experiencing one or two recurrences would be considered confirmation of an ulcer diagnosis, and eradication treatment could be employed. This approach avoids the unnecessary expense of antibiotic exposure associated with initial empiric use of $H$. pylori eradication therapy. This finding is not intended to imply that all eradication regimens are costly. From an economic perspective, however, any expenditures that do not result in a positive outcome reduce the cost-effectiveness of a selected alternative.

\section{Sensitivity Analysis}

A one-way sensitivity analysis was conducted for each variable. One-way sensitivity analysis varies the probabilities and costs used in the model, one at a time, over some reasonable range. Using this approach, the range of total costs for the $H$. pylori eradication model was $\$ 2.05-\$ 3.44$ million. The two primary cost-drivers were endoscopy and eradication therapy. For the conventional model, total costs ranged from \$1.95-\$4.92 million. The cost-drivers for the conventional model were the probability of symptom recurrence and the cost of maintenance treatment.

A second sensitivity analysis was conducted by estimating the model cost under the assumptions of using the least expensive and most expensive treatment options. Results indicated a range of $\$ 1.3-\$ 6.8$ million for the conventional model and $\$ 1.2-\$ 7.6$ million for the $H$. pylori eradication model. The high estimate for the $H$. pylori eradication model reflects the dominant influence of endoscopy cost in determining total treatment costs. The $\$ 7.6$ million estimate is based on using

Table 8. H. pylori Eradication Model Cost Estimations

\begin{tabular}{c|c|c|c}
$\begin{array}{c}\text { Costs per } \\
\text { Patient }\end{array}$ & $\begin{array}{c}\% \text { of } \\
\text { Patients }\end{array}$ & $\begin{array}{c}\text { \# of } \\
\text { Patients }\end{array}$ & Sum
\end{tabular}

New patients or existing patients without history $(\mathrm{n}=4,505)$

\begin{tabular}{l|r|l|r|l}
\hline Scenario 1 & $\$ 1,573.20$ & 0.05 & 225 & $\$ 354,363.30$ \\
\hline Scenario 2 & $\$ 1,567.50$ & 0.1 & 451 & $\$ 706,158.75$ \\
\hline Scenario 3 & $\$ 388.37$ & 0.1 & 451 & $\$ 174,960.69$ \\
\hline Scenario 4 & $\$ 353.45$ & 0.5 & 2,253 & $\$ 796,146.13$ \\
\hline Scenario 5 & $\$ 177.22$ & 0.25 & 1,125 & $\$ 199,594.03$
\end{tabular}

(T) Existing patients with history of ulcer $(n=3,495)$

\begin{tabular}{l|l|l|l|l}
\hline Scenario 6 & $\$ 132.80$ & 0.3 & 1,048 & $\$ 139,240.80$ \\
\hline Scenario 7 & $\$ 112.00$ & 0.7 & 2,447 & $\$ 274,008.00$
\end{tabular}

Total Gosts thy
Table 9. Conventional Model Cost Estimations

\begin{tabular}{l|r|c|c|c}
\hline & $\begin{array}{c}\text { Costs per } \\
\text { Patient }\end{array}$ & $\begin{array}{c}\% \text { of } \\
\text { Patients }\end{array}$ & $\begin{array}{c}\text { \# of } \\
\text { Patients }\end{array}$ & Sum \\
\hline Scenario 1 & $\$ 1,258.19$ & 0.3 & 70 & $\$ 88,325.11$ \\
\hline Scenario 2 & $\$ 1,236.40$ & 0.2 & 47 & $\$ 57,863.45$ \\
\hline Scenario 3 & $\$ 311.27$ & 0.2 & 47 & $\$ 14,567.32$ \\
\hline Scenario 4 & $\$ 234.35$ & 0.3 & 70 & $\$ 16,451.23$
\end{tabular}

Existing patients not on maintenance therapy with no history of

\begin{tabular}{l|r|r|r|r}
\hline & \multicolumn{5}{|c}{ ulcers $(\mathbf{n = 3}, \mathbf{1 8 1})$} \\
\hline Scenario 5 & $\$ 1,032.67$ & 0.1 & 318 & $\$ 328,493.53$ \\
\hline Scenario 6 & $\$ 979.66$ & 0.1 & 318 & $\$ 311,631.12$ \\
\hline Scenario 7 & $\$ 376.75$ & 0.7 & 2,227 & $\$ 838,911.90$ \\
\hline Scenario 8 & $\$ 188.27$ & 0.1 & 318 & $\$ 59,889.32$
\end{tabular}

Existing patients on maintenance therapy with history of ulcer

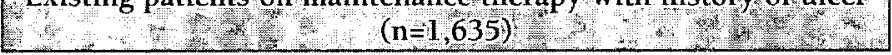

Scenario 9, $|\$ 307.39| 1.0|1,635| \$ 502,578.07$

Existing patients not on maintenance therapy with history of W 3 ulcer $(n=1,860)$

\begin{tabular}{l|l|l|l|l} 
Scenario 10: & $\$ 340.80$ & 0.8 & 1,488 & $\$ 507,104.15$ \\
\hline Scenario 11 & $\$ 164.66$ & 0.2 & 372 & $\$ 61,255.01$
\end{tabular}

$\begin{aligned} & \text { Existing patients on maintenance therapy with no history of } \\
& \text { ulcer }(n=1,090)\end{aligned}$
\begin{tabular}{l|c|c|c|c|} 
Scenario 12 & $\$ 457.61$ & 0.5 & 545 & $\$ 249,397.50$ \\
\hline Scenario 13 & $\$ 214.92$ & 0.5 & 545 & $\$ 117,134.02$ \\
\hline Total costs & & & & \\
\hline
\end{tabular}

endoscopy to diagnose ulcer prior to therapy in all eligible patients. While endoscopy for all patients offers the highest degree of specificity, the costs are also high. The lowest-cost estimates are associated with the use of empiric therapy in all potential ulcer patients. Under this situation, one-year costs will be lower; however, the use of antibiotics in patients who may not benefit is a debatable treatment strategy. Based on the sensitivity analysis, first-year costs associated with $\mathrm{H}$. pylori eradication cannot be assumed to be lower than those associated with conventional therapy. Results depend on how patients are selected and the treatment pathways they follow. If everyone who might potentially have an ulcer undergoes endoscopy, costs will be greater than if empiric therapy is used. The key to developing a management strategy for peptic ulcer disease is identifying which patients are most likely to benefit from endoscopy and reserving endoscopy for these patients. The model allows assessment of the impact on costs, as well as on cure rates, by considering the percentages of patients sent down each pathway and the numbers entered into the probability of successful treatment. 
Table 10. Sensitivity Analysis Results

\section{Analysis Variable}

Cost Estimates

(\$ in Millions)

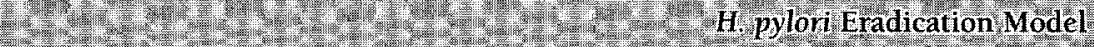

Probability of being positive for $H$. pylori and ulcer

Probability that symptoms do not recur

Probability that $H$. pylori has been eradicated but symptoms

persist and patients must be retreated or referred

Probability that $H$. pylori is present (confirmed by test)

Cost of endoscopy

Cost of H. pylori presence test

Cost of H. pylori eradication therapy

Cost of H. pylori eradication test (urea breath test)

Cost of referral

Cost of H. pylori presence test (serum)

TOTAL RANGE

MODEL ESTIMATE

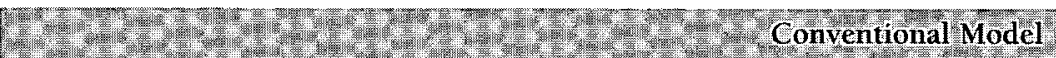

Probability that patient is positive for ulcer

Probability that symptoms resolve

Probability that symptoms do not recur

Probability that patient is compliant with maintenance therapy

Cost of endoscopy

Cost of acute ulcer therapy

Cost of maintenance therapy

Cost of referral

Cost of physician office visit

Maintenance factor for new patients

Maintenance factor for existing patients on maintenance therapy prior to recurrence

Acute factor

High compliance

Low compliance

Recurrence factor for new patients

Recurrence rate for existing patients

TOTAL RANGE

MODEL ESTIMATE



\begin{tabular}{|c|c|}
\hline Minimum & Maximium \\
\hline 2.65 & 2.63 \\
\hline 2.42 & 3.02 \\
\hline 2.64 & 2.65 \\
\hline 2.63 & 2.66 \\
\hline 2.05 & 3.20 \\
\hline 2.54 & 2.71 \\
\hline 2.25 & 3.44 \\
\hline 2.60 & 2.67 \\
\hline 2.32 & 3.07 \\
\hline 2.36 & 3.07 \\
\hline 2.05 & 3.44 \\
\hline & \\
\hline
\end{tabular}

3.12

3.01

1.95

2.96

2.51

2.76

2.56

2.99

3.12

3.15

2.98

3.03

2.89

3.02

3.11

3.11

1.95
3.21

3.24

4.16

3.27

3.75

3.94

4.92

3.37

3.42

3.16

3.45

3.28

3.41

3.24

3.31

3.22

4.92

3.15

\section{Limitations}

This model does not explicitly address compliance with $H$. pylori eradication therapy. Instead, compliance is built into the failure rate (i.e., $90 \%$ success rate). Effects of compliance on various therapies can be assessed only by changing the failure rate. The model also does not consider additional benefits that may accrue from lowering rates of gastric lymphoma. A relationship between $H$. pylori and gastric lymphoma has been reported in the literature. As the mechanism for this associa- tion becomes elucidated, this effect may need to be included in the model. This model also does not address the full range of causes of peptic ulcer disease. Ulcers due to nonsteroidal antiinflammatory use or Zollinger-Ellison syndrome are not addressed. The average costs presented in the model may not reflect actual costs for MCOs. Health care organizations that have negotiated endoscopy rates significantly different from the averages used in this model should include their own costs in the model. Finally, costs were assumed to be constant over 
the year. As costs change, estimates from the model will vary. Use of actual data rather than literature-based estimates is encouraged.

\section{DISCUSSION AND CONCLUSIONS}

H. pylori is now established as the principal cause of chronic gastritis and peptic ulcer disease. The impact of $H$. pylori eradication on clinical and economic outcomes is significant. This article uses modeling techniques to evaluate how treatment decisions affect total predicted costs for different populations of ulcer patients. The potential for preventable costs is significant given that suggested conventional treatment of ulcer includes eight weeks of acute therapy, followed by retreatment with acute therapy and maintenance if the ulcer recurs. The percentage of ulcer patients who will experience at least one recurrence within a two-year period has been estimated at $80 \% .{ }^{.1}$ Given the assumptions of our model, an $H$. pylori eradication program has the potential of reducing firstyear costs of treating ulcer disease in a managed care population. Furthermore, selection of patients in whom a history of ulcer can be documented without generating a new endoscopy could yield even greater savings. In the short run, H. pylori eradication will not affect the rate of occurrence of new ulcers; however, it may have a significant effect on the costs and utilization related to recurrence. Eradication of $H$. pylori is gaining acceptance as a first-line treatment for peptic ulcer disease.

Our findings suggests a three-stage approach to treating peptic ulcer disease when considering first-year costs. Patients who initially present with symptoms consistent with ulcer should be treated with conventional therapy. If one or more recurrences are experienced, then ulcer is likely and $\mathrm{H}$. pylori eradication should be indicated. Endoscopy should be conducted if more serious disease is suspected or if patients are nonresponsive to conventional or $\mathrm{H}$. pylori eradication therapies. MCOs need to develop and communicate ulcer management strategies that consider both eradication and acute treatment followed by maintenance therapy. If the goal of peptic ulcer disease management is to improve clinical outcomes and lower costs, this model may be used as a basis for considera- tion of how alternative strategies may be developed for several different ulcer populations.

\section{References}

1. National Institutes of Health consensus development panel. Helicobacter pylori in peptic ulcer disease. JAMA 1994; 272: 65-69.

2. O'Brien B, Goeree R, Mohamed AH, Hunt R. Cost effectiveness of Helicobacter pylori eradication for long-term management of duodenal ulcer in Canada. Arch Intern Med 1995; 155: 1958-64.

3. Imperiale TF, et al. A cost analysis of alternative treatments for duodenal ulcer. Annals of Internal Medicine 1995; 123: 665-72.

4. Fendrick AM, Chernew ME, Hirth RA, Bloom BS. Alternative management strategies for patients with suspected peptic ulcer disease. Ann Intern Med 1995; 123: 260-68.

5 . Vakil N, Fennerty MB. Cost effectiveness of treatment regimens for the eradication of Helicobacter pylori in duodenal ulcer. The American Journal of Gastroenterology 1996; 91(2): 239-45.

6. Greenberg PD, Koch J, Cello JP. Clinical utility and cost effectiveness of Heliocobacter pylori testing for patients with duodenal and gastric ulcers. The American Journal of Gastroenterology 1996; 91(2): 228-32.

7. Treiber $G$. Influence of drug dosage on Helicobacter pylori eradication: a cost effectiveness analysis. The American Journal of Gastroenterology 1996; 91(2): $246-57$

8. National Institutes of Health consensus development panel. Heliocobacter pylori in peptic ulcer disease. JAMA 1994(Jul); 272: 65-69.

9. Sonnenberg A. Peptic ulcer. In: Digestive diseases in the United States. Bethesda, MD: National Institutes of Health, 1994. Publication Number 94$1447 ; 359-408$

10. Kurata JH. Ulcer epidemiology: an overview and proposed research framework. Gastroenterology 1989; 96(Suppl 1): 569-80.

11. Van Deventer GM, et al. A randomized study of maintenance therapy with ranitidine to prevent the recurrence of duodenal ulcer. N Eng J Med 1989;

320: 1113-19.

12. Bytzer P. Empirical $\mathrm{H}_{2}$-blocker therapy or prompt endoscopy in management of dyspepsia. Lancet 1994; 343: 811-16.

13. Talley NJ, et al. Lack of discriminate value of dyspepsia subgroups in patients referred for upper endoscopy. Gastroenterology 1993; 105: 1378-86. 14. Walsh J, Peterson WL. The treatment of Helicobacter pylori infection in the management of peptic ulcer disease. N Eng J Med 1995; 333: 984-91.

15. Greenberg RE, Bank $\mathrm{S}$. The prevalence of Helicobacter pylori in nonulcer dyspepsia. Arch Int Med 1990; 150: 2053-55.

16. McCarthy C, Patchett S, Collins RM, Keane C, and O'Morain C. Longterm prospective study of Helicobacter pylori in nonulcer dyspepsia. Digestive Disease Science. 1995; 40(1): 114-119.

17. De Boer WA, et al. The best therapy for Helicobacter pylori infection: should efficacy or side effect profile determine our choice? Scand J Gastroenterology 1995; 30: 401-07. 


\section{H. pylori Eradication Model}

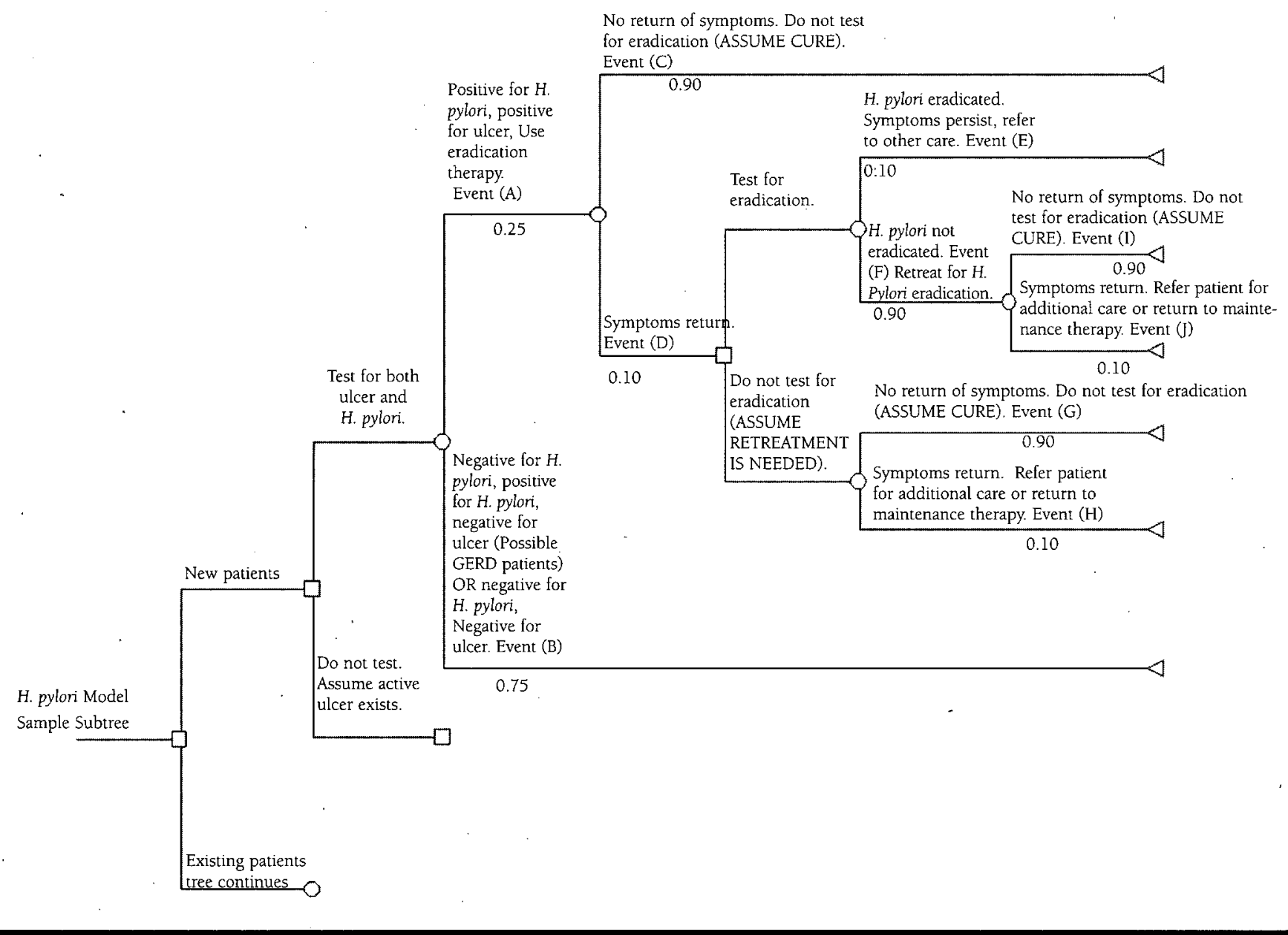




\section{Conventional Model}






\section{Appendix B. Events Probabilities for Conventional Therapy}

1. New Patients

\begin{tabular}{|c|c|c|}
\hline Name & Description & Probability \\
\hline Event (AA) & After endoscopy, the probability that the patient is positive for ulcer. & 0.25 \\
\hline Event (BB) & After endoscopy, the probability that the patient is not positive for ulcer. & 0.75 \\
\hline Event (CC) & After endoscopy and acute treatment, the probability that symptoms resolve. & 0.85 \\
\hline Event (DD) & After endoscopy and acute treatment, the probability that symptoms do not resolve. & 0.15 \\
\hline Event (EE) & After endoscopy, acute treatment, and resolution of symptoms, the probability that symptoms recur. & 0.6 \\
\hline Event (FF) & After endoscopy, acute treatment, and resolution of symptoms, the probability that symptoms do not recur. & 0.4 \\
\hline Event $(G G)$ & $\begin{array}{l}\text { After endoscopy, acute treatment, resolution of symptoms, recurrence, and retreatment, the probability that symptoms } \\
\text { resolve. }\end{array}$ & 0.9 \\
\hline Event $(\mathrm{HH})$ & $\begin{array}{l}\text { After endoscopy, acute treatment, resolution of symptoms, recurrence, and retreatment, the probability that symptoms } \\
\text { do not resolve. }\end{array}$ & 0.1 \\
\hline Event (II) & $\begin{array}{l}\text { After endoscopy, acute treatment, resolution, recurrence, retreatment, resolution, maintenance therapy, the probability } \\
\text { that the patient is compliant. }\end{array}$ & 0.75 \\
\hline Event (J) & $\begin{array}{l}\text { After endoscopy, acute treatment, resolution, recurrence, retreatment, resolution, maintenance therapy, the probability } \\
\text { that the patient is not compliant. }\end{array}$ & 0.25 \\
\hline Event $(\mathrm{KK})$ & $\begin{array}{l}\text { After endoscopy, acute treatment, resolution, recurrence, retreatment, resolution, and no maintenance therapy, the } \\
\text { probability that symptoms recur. }\end{array}$ & 0.8 \\
\hline Event (LL) & $\begin{array}{l}\text { After endoscopy, acute treatment, resolution, recurrence, retreatment, resolution, and no maintenance therapy, the } \\
\text { probability that symptoms do not recur. }\end{array}$ & 0.2 \\
\hline Event (MM) & $\begin{array}{l}\text { After endoscopy, acute treatment, resolution, recurrence, retreatment, resolution, maintenance therapy, and the patient is } \\
\text { compliant, the probability that symptoms recur. }\end{array}$ & 0.25 \\
\hline Event (NN) & $\begin{array}{l}\text { After endoscopy, acute treatment, resolution, recurrence, retreatment, resolution, maintenance therapy, and the patient is } \\
\text { compliant, the probability that symptoms do not recur. }\end{array}$ & 0.75 \\
\hline Event $(\mathrm{OO})$ & $\begin{array}{l}\text { After endoscopy, acute treatment, resolution, recurrence, retreatment, resolution, maintenance therapy, and the patient is } \\
\text { not compliant, the probability that symptoms recur. }\end{array}$ & 0.75 \\
\hline Event (PP) & $\begin{array}{l}\text { After endoscopy, acute treatment, resolution, recurrence, retreatment, resolution, maintenance therapy, and the patient is } \\
\text { not compliant, the probability that symptoms do not recur. }\end{array}$ & 0.25 \\
\hline Event $(Q Q)$ & After empiric therapy and acute treatment, the probability that symptoms resolve. & 0.75 \\
\hline Event (RR) & After empiric therapy and acute treatment, the probability that symptoms do not resolve. & 0.25 \\
\hline Event (SS) & After empiric therapy, acute treatment, and resolution of symptoms, the probability that symptoms recur. & 0.6 \\
\hline Event (TT) & After empiric therapy, acute treatment, and resolution of symptoms, the probability that symptoms do not recur. & 0.4 \\
\hline Event (UU) & $\begin{array}{l}\text { After empiric therapy, acute treatment, resolution of symptoms, recurrence, and retreatment, the probability that } \\
\text { symptoms resolve. }\end{array}$ & 0.9 \\
\hline Event (VV) & $\begin{array}{l}\text { After empiric therapy, acute treatment, resolution of symptoms, recurrence, and retreatment, the probability that } \\
\text { symptoms do not resolve. }\end{array}$ & 0.1 \\
\hline$\overline{\text { Event (WW) }}$ & $\begin{array}{l}\text { After empiric therapy, acute treatment, resolution, recurrence, retreatment, resolution, maintenance therapy, the } \\
\text { probability that the patient is compliant. }\end{array}$ & 0.75 \\
\hline Event $(\mathrm{XX})$ & $\begin{array}{l}\text { After empiric therapy, acute treatment, resolution, recurrence, retreatment, resolution, maintenance therapy, the } \\
\text { probability that the patient is not compliant. }\end{array}$ & 0.25 \\
\hline Event $(\mathrm{YY})$ & $\begin{array}{l}\text { After empiric therapy, acute treatment, resolution, recurrence, retreatment, resolution, and no maintenance therapy, the } \\
\text { probability that symptoms recur. }\end{array}$ & 0.8 \\
\hline$\overline{\text { Event }(\mathrm{ZZ})}$ & $\begin{array}{l}\text { After empiric therapy, acute treatment, resolution, recurrence, retreatment, resolution, and no maintenance therapy, the } \\
\text { probability that symptöms do not recur. }\end{array}$ & 0.2 \\
\hline Event (AAA) & $\begin{array}{l}\text { After empiric therapy, acute treatment, resolution, recurrence, retreatment, resolution, maintenance therapy, and the } \\
\text { patient is compliant, the probability that symptoms recur. }\end{array}$ & 0.25 \\
\hline Event (BBB) & $\begin{array}{l}\text { After empiric therapy, acute treatment, resolution, recurrence, retreatment, resolution, maintenance therapy, and the } \\
\text { patient is compliant, the probability that symptoms do not recur. }\end{array}$ & 0.75 \\
\hline Event (CCC) & $\begin{array}{l}\text { After empiric therapy, acute treatment, resolution, recurrence, retreatment, resolution, maintenance therapy, and the } \\
\text { patient is not compliant, the probability that symptoms recur. }\end{array}$ & 0.75 \\
\hline Event (DDD) & $\begin{array}{l}\text { After empiric therapy, acute treatment, resolution, recurrence, retreatment, resolution, maintenance therapy, and the } \\
\text { patient is not compliant, the probability that symptoms do not recur. }\end{array}$ & 0.25 \\
\hline
\end{tabular}

* Note: The percentages in the following tables were taken from the literature when available. If no literature was available then the numbers used in these tables reflect the opinions of the authors and their clinical pharmacy consultants. 


\section{Existing Maintenance Patients}

\begin{tabular}{|c|c|c|}
\hline Name & Description & Probability \\
\hline Event $(A B)$ & For patients with a history of ulcer, the probability that symptoms recur. & 0.4 \\
\hline Event (AC) & For patients with a history of ulcer, the probability that symptoms do not recur. & 0.6 \\
\hline Event (AD) & For patients with a history of ulcer, whose symptoms recur, the probability that symptoms resolve after acute treatment. & 0.9 \\
\hline Event (AE) & $\begin{array}{l}\text { For patients with a history of ulcer, whose symptoms recur, the probability that symptoms do not resolve after acute } \\
\text { trearment. }\end{array}$ & 0.1 \\
\hline Event (AF) & $\begin{array}{l}\text { For patients with a history of ulcer, whose symptoms recur, resolve after acute treatment, are placed on maintenance } \\
\text { therapy, the probability that these patients will be compliant. }\end{array}$ & 0.75 \\
\hline Event (AG) & $\begin{array}{l}\text { For patients with a history of ulcer, whose symptoms recur, resolve after acute treatment, are placed on maintenance } \\
\text { therapy, the probability that these patients will not be compliant. }\end{array}$ & 0.25 \\
\hline Event $(\mathrm{AH})$ & $\begin{array}{l}\text { For patients with a history of ulcer, whose symptoms recur, resolve after acute treatment, are placed on maintenance } \\
\text { therapy, and are compliant, the probability that symptoms will recur. }\end{array}$ & 0.4 \\
\hline Event (AI) & $\begin{array}{l}\text { For patients with a history of ulcer, whose symptoms recur, resolve after acute treatment, are placed on maintenance } \\
\text { therapy, and are compliant, the probability that symptoms will not recur. }\end{array}$ & $\overline{0.6}$ \\
\hline Event $(\mathrm{AJ})$ & $\begin{array}{l}\text { For patients with a history of ulcer, whose symptoms recur, resolve after acute treatment, are placed on maintenance } \\
\text { therapy, and are not compliant, the probability that symptoms will recur. }\end{array}$ & 0.6 \\
\hline Event $(\mathrm{AK})$ & $\begin{array}{l}\text { For patients with a history of ulcer, whose symptoms recur, resolve after acute treatment, are placed on maintenance } \\
\text { therapy, and are not compliant, the probability that symptoms will not recur. }\end{array}$ & $\overline{0.4}$ \\
\hline Event (BB) & For patients with no history of ulcer, the probability that symptoms recur. & 0.3 \\
\hline Event (BC) & For patients with no history of ulcer, the probability that symptoms do not recur. & 0.7 \\
\hline Event (BD) & $\begin{array}{l}\text { For patients with no history of ulcer, whose symptoms recur, receive endoscopy, the probability that the endoscopy } \\
\text { indicates an ulcer. }\end{array}$ & 0.25 \\
\hline Event (BE) & $\begin{array}{l}\text { For patients with no history of ulcer, whose symptoms recur, receive endoscopy, the probability that the endoscopy } \\
\text { does not indicate an ulcer. }\end{array}$ & 0.75 \\
\hline Event $(\mathrm{BF})$ & $\begin{array}{l}\text { For patients with no history of ulcer, whose symptoms recur, who do not receive endoscopy, the probability that symp- } \\
\text { toms resolve after acute treatment and are placed back on maintenance. }\end{array}$ & 0.8 \\
\hline Event (BG) & $\begin{array}{l}\text { For patients with no history of ulcer, whose symptoms recur, who do not receive endoscopy, the probability that symp- } \\
\text { toms do not resolve after acute treatment. }\end{array}$ & $\overline{0.2}$ \\
\hline Event (BH) & $\begin{array}{l}\text { For patients with no history of ulcer, whose symptoms recur, are endoscoped and positive for ulcer, the probability that } \\
\text { they resolve after acute treatment and are placed back on maintenance therapy. }\end{array}$ & 0.9 \\
\hline Event (BI) & $\begin{array}{l}\text { For patients with no history of ulcer, whose symptoms recur, are endoscoped and positive for ulcer, the probability that } \\
\text { they do not resolve after acute treatment. }\end{array}$ & 0.1 \\
\hline Event (BJ) & $\begin{array}{l}\text { For patients with no history of ulcer, whose symptoms recur, are not endoscoped, resolve after acute treatment, are } \\
\text { placed on maintenance therapy, the probability that these patients will be compliant. }\end{array}$ & 0.75 \\
\hline Event (BK) & $\begin{array}{l}\text { For patients with no history of ulcer, whose symptoms recur, are not endoscoped, resolve after acute treatment, are placed } \\
\text { on maintenance therapy, the probability that these patients will be noncompliant. }\end{array}$ & 0.25 \\
\hline Event (BL) & $\begin{array}{l}\text { For patients with no history of ulcer, whose symptoms recur, are endoscoped and positive for ulcer, resolve after acute } \\
\text { treatment, are placed on maintenance therapy, the probability that these patients will be compliant. }\end{array}$ & 0.75 \\
\hline Event (BM) & $\begin{array}{l}\text { For patients with no history of ulcer, whose symptoms recur, are endoscoped and positive for ulcer, resolve after acute } \\
\text { treatment, are placed on maintenance therapy, the probability that these patients will not be compliant. }\end{array}$ & 0.25 \\
\hline Event (BN) & $\begin{array}{l}\text { For patients with no history of ulcer, whose symptoms recur, are not endoscoped, resolve after acute treatment, are } \\
\text { placed back on maintenance therapy, are compliant, the probability that symptoms will recur. }\end{array}$ & 0.4 \\
\hline Event (BO) & $\begin{array}{l}\text { For patients with no history of ulcer, whose symptoms recur, are not endoscoped, resolve after acute treatment, are } \\
\text { placed back on maintenance therapy, are compliant, the probability that symptoms will not recur. }\end{array}$ & $\overline{0.6}$ \\
\hline Event (BP) & $\begin{array}{l}\text { For patients with no history of ulcer, whose symptoms recur, are not endoscoped, resolve áfter acute treatment, are } \\
\text { placed back on maintenance therapy, are not compliant, the probability that symptoms will recur. }\end{array}$ & 0.6 \\
\hline Event (BQ) & $\begin{array}{l}\text { For patients with no history of ulcer, whose symptoms recur, are not endoscoped, resolve after acute treatment, are placed } \\
\text { back on maintenance therapy, are not compliant, the probability that symptoms will not recur. }\end{array}$ & 0.4 \\
\hline Event (BR) & $\begin{array}{l}\text { For patients with no history of ulcer, whose symptoms recur, are endoscoped and positive for ulcer, resolve after acute } \\
\text { treatment, are placed on maintenance therapy, are compliant, the probability that symptoms will recur. }\end{array}$ & 0.4 \\
\hline
\end{tabular}


2. Existing Maintenance Patients (continued)

\begin{tabular}{l|l|c}
\hline Name & Description & Probability \\
\hline Event (BS) & $\begin{array}{l}\text { For patients with no history of ulcer, whose symptoms recur, are endoscoped and positive for ulcer, resolve after acute } \\
\text { treatment, are placed on maintenance therapy, are compliant, the probability that symptoms will not recur. }\end{array}$ & 0.6 \\
\hline Event (BT) & $\begin{array}{l}\text { For patients with no history of ulcer, whose symptoms recur, are endoscoped and positive for ulcer, resolve after acute } \\
\text { treatment, are placed on maintenance therapy, are not compliant, the probability that symptoms will recur. }\end{array}$ & $\begin{array}{l}\text { For patients with no history of ulcer, whose symptoms recur, are endoscoped and positive for ulcer, resolve after acute } \\
\text { treatment, are placed on maintenance therapy, are not compliant, the probability that symptoms will not recur. }\end{array}$ \\
\hline Event (BU) & \begin{tabular}{l} 
For \\
\hline
\end{tabular}
\end{tabular}

\section{Existing Patients Not on Maintenance Therapy}

\begin{tabular}{|c|c|c|}
\hline Name & Description & Probability \\
\hline Event $(C B)$ & For patients with a history of ulcer, the probability that symptoms recur. & 0.6 \\
\hline Event (CC) & For patients with a history of ulcer, the probability that symptoms do not recur. & 0.4 \\
\hline Event (CD) & For patients with a history of ulcer, whose symptoms recur, the probability that symptoms resolve after acute treatment. & 0.9 \\
\hline Event (CE) & $\begin{array}{l}\text { For patients with a history of ulcer, whose symptoms recur, the probability that symptoms do not resolve after acute } \\
\text { treatment. }\end{array}$ & 0.1 \\
\hline Event $(\mathrm{CF})$ & $\begin{array}{l}\text { For patients with a history of ulcer, whose symptoms recur, resolve after acute treatment, are placed on maintenance } \\
\text { therapy, the probability that these patients will be compliant. }\end{array}$ & 0.75 \\
\hline Event (CG) & $\begin{array}{l}\text { For patients with a history of ulcer, whose symptoms recur, resolve after acute treatment, are placed on maintenance } \\
\text { therapy, the probability that these patients will not be compliant. }\end{array}$ & 0.25 \\
\hline Event $(\mathrm{CH})$ & $\begin{array}{l}\text { For patients with a history of ulcer, whose symptoms recur, resolve after acute treatment, are not placed on maintenance } \\
\text { therapy, the probability that these symptoms will recur. }\end{array}$ & 0.8 \\
\hline Event $(\mathrm{Cl})$ & $\begin{array}{l}\text { For patients with a history of ulcer, whose symptoms recur, resolve after acute treatment, are not placed on maintenance } \\
\text { therapy, the probability that these symptoms will not recur. }\end{array}$ & $\overline{0.2}$ \\
\hline Event $(C J)$ & $\begin{array}{l}\text { For patients with a history of ulcer, whose symptoms recur, resolve after acute treatment, are placed on maintenance } \\
\text { therapy, and are compliant, the probability that symptoms will recur. }\end{array}$ & 0.4 \\
\hline Event (CK) & $\begin{array}{l}\text { For patients with a history of ulcer, whose symptoms recur, resolve after acute treatment, are placed on maintenance } \\
\text { therapy, and are compliant, the probability that symptoms will not recur. }\end{array}$ & 0.6 \\
\hline$\overline{\text { Event (CL) }}$ & $\begin{array}{l}\text { For patients with a history of ulcer, whose symptoms recur, resolve after acute treatment, are placed on maintenance } \\
\text { therapy, and are not compliant, the probability that symptoms will recur. }\end{array}$ & 0.6 \\
\hline Event (CM) & $\begin{array}{l}\text { For patients with a history of ulcer, whose symptoms recur, resolve after acute treatment, are placed on maintenance } \\
\text { therapy, and are not compliant, the probability that symptoms will not recur. }\end{array}$ & 0.4 \\
\hline Event (DB) & For patients with no history of ulcer, the probability that symptoms recur. & 0.7 \\
\hline Event (DC) & For patients with no history of ulcer, the probability that symptoms do not recur. & 0.3 \\
\hline Event (DD) & $\begin{array}{l}\text { For patients with no history of ulcer, whose symptoms recur, receive endoscopy, the probability that the endoscopy } \\
\text { indicates an ulcer. }\end{array}$ & 0.25 \\
\hline Event (DE) & $\begin{array}{l}\text { For patients with no history of ulcer, whose symptoms recur, receive endoscopy, the probability that the endoscopy } \\
\text { does not indicate an ulcer. }\end{array}$ & 0.75 \\
\hline Event (DF) & $\begin{array}{l}\text { For patients with no history of ulcer, whose symptoms recur, who do not receive endoscopy, the probability that } \\
\text { symptoms resolve after acute treatment. }\end{array}$ & 0.8 \\
\hline Event (DG) & $\begin{array}{l}\text { For patients with no history of ulcer, whose symptoms recur, who do not receive endoscopy, the probability that } \\
\text { symptoms do not resolve after acute treatment. }\end{array}$ & 0.2 \\
\hline Event (DH) & $\begin{array}{l}\text { For patients with no history of ulcer, whose symptoms recur, are endoscoped and positive for ulcer, the probability that } \\
\text { they resolve after acute treatment. }\end{array}$ & 0.9 \\
\hline Event (DI) & $\begin{array}{l}\text { For patients with no history of ulcer, whose symptoms recur, are endoscoped and positive for ulcer, the probability that } \\
\text { they do not resolve after acute treatment. }\end{array}$ & 0.1 \\
\hline Event (DJ) & $\begin{array}{l}\text { For patients with no history of ulcer, whose symptoms recur, are not endoscoped, resolve after acute treatment, are } \\
\text { placed on maintenance therapy, the probability that these patients will be compliant. }\end{array}$ & 0.75 \\
\hline Event (DK) & $\begin{array}{l}\text { For patients with no history of ulcer, whose symptoms recur, are not endoscoped, resolve after acute treatment, are } \\
\text { placed on maintenance therapy, the probability that these patients will not be compliant. }\end{array}$ & 0.25 \\
\hline
\end{tabular}


3. Existing Patients Not on Maintenance Therapy (continued)

\begin{tabular}{|c|c|c|}
\hline Name & Description & Probability \\
\hline Event (DL) & $\begin{array}{l}\text { For patients with no history of ulcer, whose symptoms recur, are not endoscoped, resolve after acute treatment, are not } \\
\text { placed on maintenance therapy, the probability that these symptoms will recur. }\end{array}$ & 0.6 \\
\hline Event (DM) & $\begin{array}{l}\text { For patients with no history of ulcer, whose symptoms recur, are not endoscoped, resolve after acute treatment, are not } \\
\text { placed on maintenance therapy, the probability that these symptoms will not recur. }\end{array}$ & 0.4 \\
\hline Event (DN) & $\begin{array}{l}\text { For patients with no history of ulcer, whose symptoms recur, are endoscoped and positive for ulcer, resolve after acute } \\
\text { treatment, are placed on maintenance therapy, the probability that these patients will be compliant. }\end{array}$ & 0.75 \\
\hline Event (DO) & $\begin{array}{l}\text { For patients with no history of ulcer, whose symptoms recur, are endoscoped and positive for ulcer, resolve after acute } \\
\text { treatment, are placed on maintenance therapy, the probability that these patients will not be compliant. }\end{array}$ & 0.25 \\
\hline Event (DP) & $\begin{array}{l}\text { For patients with no history of ulcer, whose symptoms recur, are endoscoped, resolve after acute treatment, are not } \\
\text { placed on maintenance therapy, the probability that these symptoms will recur. }\end{array}$ & 0.6 \\
\hline Event (DQ) & $\begin{array}{l}\text { For patients with no history of ulcer, whose symptoms recur, are endoscoped, resolve after acute treatment, are not } \\
\text { placed on maintenance therapy, the probability that these symptoms will not recur. }\end{array}$ & 0.4 \\
\hline Event (DR) & $\begin{array}{l}\text { For patients with no history of ulcer, whose symptoms recur, are not endoscoped, resolve after acute treatment, are } \\
\text { placed on maintenance therapy, are compliant, the probability that symptoms will recur. }\end{array}$ & 0.4 \\
\hline Event (DS) & $\begin{array}{l}\text { For patients with no history of ulcer, whose symptoms recur, are not endoscoped, resolve after acute treatment, are } \\
\text { placed back on maintenance therapy, are compliant, the probability that symptoms will not recur. }\end{array}$ & 0.6 \\
\hline Event (DT) & $\begin{array}{l}\text { For patients with no history of ulcer, whose symptoms recur, are not endoscoped, resolve after acute treatment, are } \\
\text { placed back on maintenance therapy, are not compliant, the probability that symptoms will recur. }\end{array}$ & 0.6 \\
\hline Event (DU) & $\begin{array}{l}\text { For patients with no history of ulcer, whose symptoms recur, are not endoscoped, resolve after acute treatment, are } \\
\text { placed back on maintenance therapy, are not compliant, the probability that symptoms will not recur. }\end{array}$ & 0.4 \\
\hline Event (DV) & $\begin{array}{l}\text { For patients with no history of ulcer, whose symptoms recur, are endoscoped and positive for ulcer, resolve after acute } \\
\text { treatment, are placed on maintenance therapy, are compliant, the probability that symptoms will recur. }\end{array}$ & 0.4 \\
\hline Event (DW) & $\begin{array}{l}\text { For patients with no history of ulcer, whose symptoms recur, are endoscoped and positive for ulcer, resolve after acute } \\
\text { treatment, are placed on maintenance therapy, are compliant, the probability that symptoms will not recur. }\end{array}$ & 0.6 \\
\hline Event (DX) & $\begin{array}{l}\text { For patients with no history of ulcer, whose symptoms recur, are endoscoped and positive for ulcer, resolve after acute } \\
\text { treatment, are placed on maintenance therapy, are not compliant, the probability that symptoms will recur. }\end{array}$ & 0.6 \\
\hline Event (DY) & $\begin{array}{l}\text { For patients with no history of ulcer, whose symptoms recur, are endoscoped and positive for ulcer, resolve after acute } \\
\text { treatment, are placed on maintenance therapy, are not compliant, the probability that symptoms will not recur. }\end{array}$ & 0.4 \\
\hline
\end{tabular}

\section{Appendix C. Events Probabilities for H. pylori Eradication Therapy}

\section{New or Existing Patients Without Ulcer History}

\begin{tabular}{|c|c|c|}
\hline Name & Description & Probability \\
\hline Event (A) & After endoscopy and test for presence of h.pylori, the probability of being positive for h.pylori and ulcer or gastritis. & 0.25 \\
\hline Event (B) & $\begin{array}{l}\text { After endoscopy and test for presence of h.pylori, the probability of being either: 1) negative for h.pylori and positive for } \\
\text { ulcer, 2) positive for h.pylori and negative for ulcer, or 3) negative for h.pylori and ulcer. }\end{array}$ & 0.75 \\
\hline Event (C) & After endoscopy, positive test, and eradication therapy, the probability that symptoms do not recur. & 0.9 \\
\hline Event (D) & After endoscopy, positive test, and eradication therapy, the probability that symptoms recur. & 0.1 \\
\hline Event $(\mathrm{E})$ & $\begin{array}{l}\text { After endoscopy, positive test, eradication therapy, symptom recurrence, and administration of eradication test, the } \\
\text { probability that h.pylori has been eradicated but symptoms still persist. }\end{array}$ & 0.1 \\
\hline Event $(\mathrm{F})$. & $\begin{array}{l}\text { After endoscopy, positive test, eradication therapy, symptom recurrence, and administration of eradication test, the } \\
\text { probability that h.pylori has been not been eradicated and retreatment for eradication. }\end{array}$ & 0.9 \\
\hline Event $(G)$ & $\begin{array}{l}\text { After endoscopy, positive test, and eradication therapy, symptoms recurrence, no eradication test, and retreatment, the } \\
\text { probability that symptoms do not recur. }\end{array}$ & 0.9 \\
\hline Event $(\mathrm{H})$ & $\begin{array}{l}\text { After endoscopy, positive test, and eradication therapy, symptoms recurrence, no eradication test, and retreatment, the } \\
\text { probability that symptoms recur. }\end{array}$ & 0.1 \\
\hline Event (I) & $\begin{array}{l}\text { After endoscopy, positive test, eradication therapy, symptom recurrence, and administration of eradication test, indication } \\
\text { that h.pylori has been not been eradicated and retreatment for eradication, the probability that symptoms do not recur. }\end{array}$ & 0.9 \\
\hline
\end{tabular}

Continued on page 220 
1. New or Existing Patients Without Ulcer History (continued)

\begin{tabular}{|c|c|c|}
\hline Name & Description & Probability \\
\hline Event.(J) & $\begin{array}{l}\text { After endoscopy, positive test, eradication therapy, symptom recurrence, and administration of eradication test, indica- } \\
\text { tion that h.pylori has been not been eradicated and retreatment for eradication, the probability that symptoms recur. }\end{array}$ & 0.1 \\
\hline Event (K) & After ulcer disease is assumed (no endoscopy), and test for presence of h.pylori, the probability that $h$. pylori is present. & 0.65 \\
\hline Event (L) & After ulcer disease is assumed (no endoscopy), and test for presence of h.pylori, the probability that h.pylori is not present. & 0.35 \\
\hline Event (M) & $\begin{array}{l}\text { After ulcer disease is assumed (no endoscopy), and no test for presence of } h \text { pylori is conducted, the probability that } \\
\text { symptoms do not recur. }\end{array}$ & 0.67 \\
\hline Event $(\mathrm{N})$ & $\begin{array}{l}\text { After ulcer disease is assumed (no endoscopy), and no test for presence of h.pylori is conducted, the probability that } \\
\text { symptoms recur. }\end{array}$ & 0.33 \\
\hline Event $(\mathrm{O})$ & $\begin{array}{l}\text { After ulcer disease is assumed (no endoscopy), test for presence of h.pylori, h.pylori is present, and eradication therapy is } \\
\text { used, the probability symptoms do not recur. }\end{array}$ & 0.55 \\
\hline Event (P) & $\begin{array}{l}\text { After ulcer disease is assumed (no endoscopy), test for presence of h.pylori, h.pylori is present, and eradication therapy is } \\
\text { used, the probability symptoms recur. }\end{array}$ & 0.45 \\
\hline Event (Q) & $\begin{array}{l}\text { After ulcer disease is assumed (no endoscopy), no test for presence of h.pylori is conducted, symptoms recur, and } \\
\text { retreatment, the probability that symptoms do not recur. }\end{array}$ & 0.33 \\
\hline Event (R) & $\begin{array}{l}\text { After ulcer disease is assumed (no endoscopy), no test for presence of h.pylori is conducted, symptoms recur, and } \\
\text { retreatment, the probability that symptoms recur. }\end{array}$ & 0.67 \\
\hline Event (S) & $\begin{array}{l}\text { After ulcer disease is assumed (no endoscopy), test for presence of } h \text {. pylori, } h \text {. pylori is present, eradication therapy is used, } \\
\text { symptoms recur, test for eradication is administered, the probability that } h \text {. pylori is eradicated and symptoms persist. }\end{array}$ & 0.9 \\
\hline Event $(\mathrm{T})$ & $\begin{array}{l}\text { After ulcer disease is assumed (no endoscopy), test for presence of } h \text {. pylori, } h \text {. pylori is present, eradication therapy is } \\
\text { used, symptoms recur, test for eradication is administered, the probability that } h \text {. pylori is not eradicated and retreat- } \\
\text { ment is administered. }\end{array}$ & 0.1 \\
\hline Event (U) & $\begin{array}{l}\text { After ulcer disease is assumed (no endoscopy), test for presence of h.pylori is used, symptoms return after eradication } \\
\text { therapy, retreatment for eradication is administered, the probability that symptoms do not recur. }\end{array}$ & 0.33 \\
\hline Event (V) & $\begin{array}{l}\text { After ulcer disease is assumed (no endoscopy), test for presence of h.pylori is used, symptoms return after eradication } \\
\text { therapy, retreatment for eradication is administered, the probability that symptoms recur. }\end{array}$ & 0.67 \\
\hline Event (W) & $\begin{array}{l}\text { After ulcer disease is assumed (no endoscopy), test for presence of h.pylori, h.pylori is present, eradication therapy is } \\
\text { used, symptoms recur, test for eradication is administered, h.pylori is not eradicated and retreatment is administered, the } \\
\text { probability that symptoms do not recur. }\end{array}$ & 0.33 \\
\hline Event $(\mathrm{X})$ & $\begin{array}{l}\text { After ulcer disease is assumed (no endoscopy), test for presence of h.pylori, h.pylori is present, eradication therapy is } \\
\text { used, symptoms recur, test for eradication is administered, h.pylori is not eradicated and retreatment is administered, the } \\
\text { probability that symptoms recur. }\end{array}$ & 0.67 \\
\hline
\end{tabular}

\section{Existing Maintenance Patients with Ulcer History}

\begin{tabular}{|c|c|c|}
\hline Name & Description & Probability \\
\hline Event (AA) & $\begin{array}{l}\text { For existing patients with a history of ulcer by endoscopy or recurrence and who receive eradication therapy, the proba- } \\
\text { bility that symptoms do not recur. }\end{array}$ & 0.9 \\
\hline Event (BB) & $\begin{array}{l}\text { For existing patients with a history of ulcer by endoscopy or recurrence and who receive eradication therapy, the proba- } \\
\text { bility that symptoms recur. }\end{array}$ & 0.1 \\
\hline Event (CC) & $\begin{array}{l}\text { For existing patients with a history of ulcer by endoscopy or recurrence, receive eradication therapy, symptoms recur, } \\
\text { they are tested for eradication, the probability that } h \text {.pylori is eradicated and symptoms still persist. }\end{array}$ & 0.1 \\
\hline Event (DD) & $\begin{array}{l}\text { For existing patients with a history of ulcer by endoscopy or recurrence, receive eradication therapy, symptoms recur, } \\
\text { they are tested for eradication, the probability that h.pylori is not eradicated and retreatment is administered. }\end{array}$ & 0.9 \\
\hline Event (EE) & $\begin{array}{l}\text { For existing patients with a history of ulcer by endoscopy or recurrence and who receive eradication therapy, symptoms } \\
\text { recur, and retreatment is administered, the probability that symptoms do not recur. }\end{array}$ & 0.9 \\
\hline Event (FF) & $\begin{array}{l}\text { For existing patients with a history of ulcer by endoscopy or recurrence and who receive eradication therapy, symptoms } \\
\text { recur, and retreatment is administered, the probability that symptoms recur. }\end{array}$ & 0.1 \\
\hline Event (GG) & $\begin{array}{l}\text { For existing patients with a history of ulcer by endoscopy or recurrence, receive eradication therapy, symptoms recur, } \\
\text { they are tested for eradication, h.pylori is not eradicated and retreatment is administered, the probability that symptoms } \\
\text { do not recur. }\end{array}$ & 0.9 \\
\hline Event $(\mathrm{HH})$ & $\begin{array}{l}\text { For existing patients with a history of ulcer by endoscopy or recurrence, receive eradication therapy, symptoms recur, they } \\
\text { are tested for eradication, h.pylori is not eradicated and retreatment is administered, the probability that symptoms recur. }\end{array}$ & 0.1 \\
\hline
\end{tabular}

